\title{
Um método para gerenciamento do processo de fiscalização dos recursos hídricos
}

\author{
André Luiz F. Alves ${ }^{1}$, Hélisson L. Nascimento ${ }^{2}$, Cláudio de Souza Baptista² ${ }^{2}$ Hugo \\ Feitosa de Figueirêdo ${ }^{3}$, Érica S. A. B. de Almeida ${ }^{3}$ \\ ${ }^{1}$ Instituto Federal do Ceará - IFCE \\ ${ }^{2}$ Laboratório de Sistemas de Informação/Unidade Acadêmica de Sistemas e \\ Computação - Universidade Federal de Campina Grande - UFCG. \\ ${ }^{3}$ Instituto Federal da Paraíba - IFPB \\ ${ }^{4}$ Agência Executiva de Gestão das Águas do Estado da Paraíba - AESA

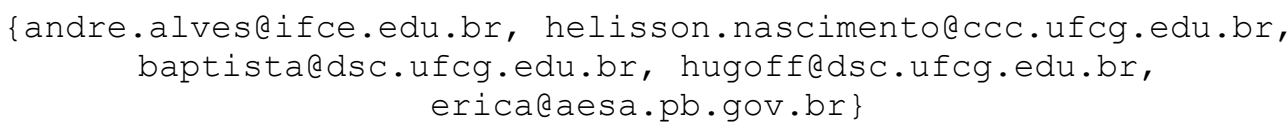

Abstract. Water has become a concern throughout the planet because it has become a scarce resource in recent years, due to several factors, especially the disrespect of human being for sustainable development. Nowadays, it is imperative to create public policies, legislation and the proposal of new methodologies, processes and products that can help in the fight against pollution, waste and rational use of water resources. Particularly, the use of information technology provides a modern, agile and efficient management of water resources. One of the important actions in this sense is the water use surveillance. In this article, we discuss the surveillance process, we approach a surveillance methodology used in the Water Management Agency, and we present a Web-based information system architecture and a mobile platform to provide a management of the surveillance in an efficient and effective way. The proposed system is already online at agency and some partial results, especially regarding the denunciations, notifications and proceedings are discussed.

Resumo. A água tem se tornado uma preocupação em todo planeta por estar se tornando um recurso cada vez mais escasso nos últimos anos, devido a diversos fatores, sobretudo ao desrespeito dos seres humanos ao desenvolvimento sustentado. Hodiernamente, torna-se imperativo a proposição de políticas públicas, legislação e desenvolvimento de novas metodologias, processos e produtos que possam auxiliar no combate à poluição, desperdicio e uso racional dos recursos hídricos. Em especial, o uso de tecnologia da informação propicia uma gestão moderna, ágil e eficiente dos recursos hídricos. Uma das ações importantes neste sentido é o processo de fiscalização do uso da água. Neste artigo, discutimos o processo de fiscalização, abordamos uma metodologia de fiscalização usada na Agência de gestão de águas, e abordamos uma arquitetura de sistema de informações baseado na Web e em plataforma móvel para prover uma gestão da fiscalização de forma eficiente e eficaz. Tal sistema encontra-se em produção na Agência de gestão de águas e alguns resultados parciais, sobretudo no tocante às denúncias, notificações e autos que são discutidos. 


\section{Introdução}

Todos sabemos que a água é um bem essencial à vida. Infelizmente, é de conhecimento público também que esse bem tem se tornado escasso devido a diversos fatores, incluindo as ações humanas em desrespeito ao desenvolvimento sustentável, aquecimento global, derretimento das geleiras, dentre outros. Existem estimativas da ONU predizendo que até o ano de 2025 mais de 3 bilhões de pessoas estarão com dificuldades de encontrar água potável para suas necessidades básicas, especialmente aquelas que residem em países que têm histórico de escassez deste líquido precioso. Particularmente no Brasil, apesar de termos uma das maiores reservas de água doce do mundo, destacando-se as bacias do Amazonas, São Francisco e Paraná, existem regiões semiáridas nas quais há escassez de água devido à ocorrência de secas duradouras e cíclicas, o que tem desafiado os poderes públicos em propor soluções para remediar este problema, através, por exemplo, de programas de transposição de água, como é o caso do Projeto de Transposição do Rio São Francisco.

Do ponto de vista jurídico, há um arcabouço legislativo, planos nacionais e estaduais de recursos hídricos, com ações envolvendo a cobrança do uso da água, fiscalização de uso não autorizado, gestão de reservatórios e segurança de barragens, gestão da qualidade das águas, monitoramento hidrometereológico, dentre outras. Este artigo, fruto de um projeto de P\&D junto a Agência Executiva de Gestão das Águas do Estado da Paraíba (AESA), aborda uma destas ações: a fiscalização do uso da água, que visa reduzir o uso não autorizado, ou seja, ilegal, da água em um estado brasileiro. Propomos uma metodologia de fiscalização que pode ser usada em qualquer Agência de Gestão de Águas através de uma solução computacional que utiliza uma arquitetura de sistema de informações baseado na Web e em plataforma móvel para prover uma gestão da fiscalização de forma eficiente e eficaz.

\section{Trabalhos Relacionados}

Em edições anteriores do WCAMA, alguns artigos trataram de métodos para auxiliar na gestão de recursos naturais que utilizavam sistemas de informação para facilitar a implantação do processo. Nesta seção, alguns desses artigos são destacados.

Andreis et al. (2016) propuseram uma aplicação móvel para monitorar a propagação da doença Ferrugem Asiática na cultura de soja brasileira. A aplicação envia informações sobre novas contaminações por meio de uma rede colaborativa de agentes responsáveis pelo gerenciamento da propagação da doença. Souza et al. (2015) desenvolveram um sistema web para monitoramento hídrico residencial utilizando uma rede sem fio de sensores. Jeronimo et al. (2015) propuseram um método para monitoramento e fiscalização de ocorrências nas bordas de reservatórios que utiliza um aplicativo móvel e um sistema web para registro das ocorrências em campo e análise posterior. Entretanto, o método proposto não aborda a geração em campo do auto de infração e do termo de compromisso dos responsáveis pelas irregularidades encontradas na fiscalização.

Tavares et al. (2011) propuseram um método que utiliza um sistema de informação geográfica como apoio no processo de estudos hidrológicos para determinar pontos de vazão para outorga. Entretanto, no método proposto não é abordada a fiscalização dos pontos de captação. Marques et al. (2009) criaram um sistema de apoio à análise da vulnerabilidade natural à poluição de recursos hídricos. Entretanto, nesse 
sistema não foi abordado a fiscalização do uso indevido ou má utilização de recursos hídricos. Oliveira e Zeilhofer (2017) desenvolveram um sistema de suporte à decisão baseado em lógica fuzzy para outorga de recursos hídricos. Entretanto, não foi abordada na proposta a fiscalização das outorgas.

Alguns outros trabalhos publicados no WCAMA podem servir como base para trabalhos futuros relacionados à fiscalização de utilização irregular de recursos hídricos. Figueiredo et al. (2016) propuseram uma biblioteca digital multimídia para gestão de documentos ambientais. Alves et al. (2015) utilizaram técnicas de análise de sentimento para analisar tweets relacionados ao meio ambiente. Santana et al. (2015) propuseram um método para gerenciamento do processo de licenciamento ambiental e implantaram um sistema que implementa o método em uma Companhia de Geração de energia Elétrica.

Júnior et al. (2013) propuseram a criação de um atlas eletrônico analítico como ferramenta na gestão dos recursos hídricos. Entretanto, a solução proposta limita-se ao problema da identificação da localização de recursos importantes para a gestão hídrica, e.g., postos pluviométricos, postos fluviométricos, barragens e fontes para abastecimento urbano. Meier, Costa e Basso (2015) descreveram a importância da participação da sociedade na gestão de recursos hídricos, destacando a legislação brasileira e portuguesa.

A FUNCEME (Sakamoto et al., 2016) desenvolveu sistema de informação para auxiliar na tomada de decisão pelo setor agrícola utilizando uma base de dados com informações diversas relacionadas à gestão de recursos hídricos. Pereira e Cavalcanti (2016) propuseram um sistema de suporte à decisão para gestão de recursos hídricos, o qual utiliza informações da rede de fluxo hídrica, dos reservatórios, das demandas e afluentes para realizar simulações.

Não foi encontrado trabalho na literatura que tenha proposto um método para fiscalizar o uso de recursos hídricos utilizando aplicativo móvel e realizando notificações com registro biométrico da ciência da autuação.

\section{Aspectos Legais no Processo de Fiscalização do Uso dos Recursos Hídricos}

Dada a importância do planeta melhor gerir suas águas, controlando o uso indevido, apoiando ações para reduzir o consumo desnecessário, evitando a poluição de rios e mananciais de água doce, dentre outros, faz-se necessário que os poderes públicos, criem leis para garantir a existência de água potável para suas respectivas populações. No Brasil, visando tão somente implementar a gestão eficiente e eficaz dos Recursos Hídricos Brasileiros, foi criada a Lei Federal 9.433/97, acompanhada pela Lei 9.984/2000 que cria a Agência Nacional de Águas - ANA, cuja regulamentação ocorreu pelo Decreto $\mathrm{n}^{\circ}$ 3.692/2000. No Estado da Paraíba, mais precisamente no ano de 2005, por intermédio da lei 7.779/05, foi criada a Agência Executiva de Gestão das Águas do Estado da Paraíba (AESA), que tem em como missão, regularizar o uso das águas dos rios e lagos de domínio da Paraíba, garantindo o seu uso sustentável, assim, evitando a poluição e o desperdício, por conseguinte, assegurando água de boa qualidade e em quantidade suficiente para a atual e as futuras gerações.

Compete, pois, a AESA a ação fiscalizadora do uso da água. Destarte, a AESA possui dentre suas atribuições a de fiscalizar, com poder de polícia, a construção e as condições operacionais de poços, barragens e outras obras de aproveitamento hidráulico, os usos de recursos hídricos superficiais e subterrâneos e a infraestrutura deles resultantes 
nos corpos de água de domínio estadual e mediante delegação expressa, nos corpos de água de bacias hidrográficas de domínio da União que ocorrem em território paraibano.

A fiscalização como instrumento meio de alcance à regularização do uso da água, enquanto insumo de produtividade, dos recursos hídricos se constitui de um dos mais importantes instrumentos de gestão, que pode ser definida como uma atividade de controle e monitoramento dos diferentes usos destes recursos. A principal finalidade da fiscalização é disciplinar pedagógica ou punitivamente os usos múltiplos previstos para a água. Esta prática é fundamental para aplicação da Política de Recursos Hídricos e pode ser definida como a atividade de controle e monitoramento para garantia racional da água de forma responsável.

Dentre suas atribuições, além do mencionado, tem o dever de sanar conflitos de uso da água no atendimento às demandas ao Ministério Público, bem como no atendimento às denúncias recebidas de terceiros, ferramenta pela qual a comunidade fornece o conhecimento de um fato contrário à legislação. Identificando qualquer irregularidade, deve ser aplicado pelo Agente de Fiscalização um ato administrativo, Auto de Constatação, notificação com vistas a regularizar um uso contrário à legislação vigente ou Termo de Compromisso, como pactuação bilateral de compromissos visando sanar irregularidades. Essa atividade tem caráter preventivo e/ou punitivo, na medida em que faça ver aos usuários da respectiva água o restrito cumprimento da legislação vigente, bem como a necessidade de regularização dos usos múltiplos amparados nos princípios legais. Para uma maior eficiência e eficácia no processo de fiscalização, o uso de sistemas de informação dotados de geoprocessamento, recursos multimídia e com implementação via Web e via plataforma móvel são mandatórios.

\section{Metodologia Proposta}

Compreendendo a complexidade envolvida na gestão de recursos hídricos, que segundo a legislação e normas vigentes transpassa ações destinadas a regular o uso, o controle e a proteção dos recursos hídricos, foi projetada uma metodologia para gerenciar as informações relativas ao processo de fiscalização do uso dos recursos hídricos. Devido à pluralidade de ações envolvidas no processo de fiscalização, foi arquitetada uma solução flexível para organização das informações coletadas durante as ações realizadas em todo o processo de fiscalização, desde a recepção de uma denúncia pública até a uma vistoria que possibilitasse o devido cumprimento das legislações e normas vigentes, possibilitando uma fiscalização eficaz dos recursos hídricos.

Outro ponto de destaque na solução proposta foi a inclusão de sensores inteligentes através da colaboração da população realizando denúncias relativas a má utilização dos recursos hídricos, o que permite uma fiscalização mais eficaz. Trata-se, pois, de fomentar o controle social na fiscalização do uso da água. Nesta perspectiva, apoiada no conceito de crowdsourcing na qual "uso das habilidades perceptuais e cognitivas de um grupo de indivíduos para resolver um problema" (Erickson, 2010) a população torna-se um agente ativo no processo de fiscalização e neste sentido ela acompanha o resultado de sua participação no processo.

O processo de fiscalização integra as atividades desde a recepção de denúncias até o cadastro de um requerimento de abertura de processo civil contra o infrator. A Figura 1 sintetiza o fluxo dos processos envolvidos na fiscalização dos recursos hídricos que embasaram a implementação da solução computacional proposta neste trabalho. 


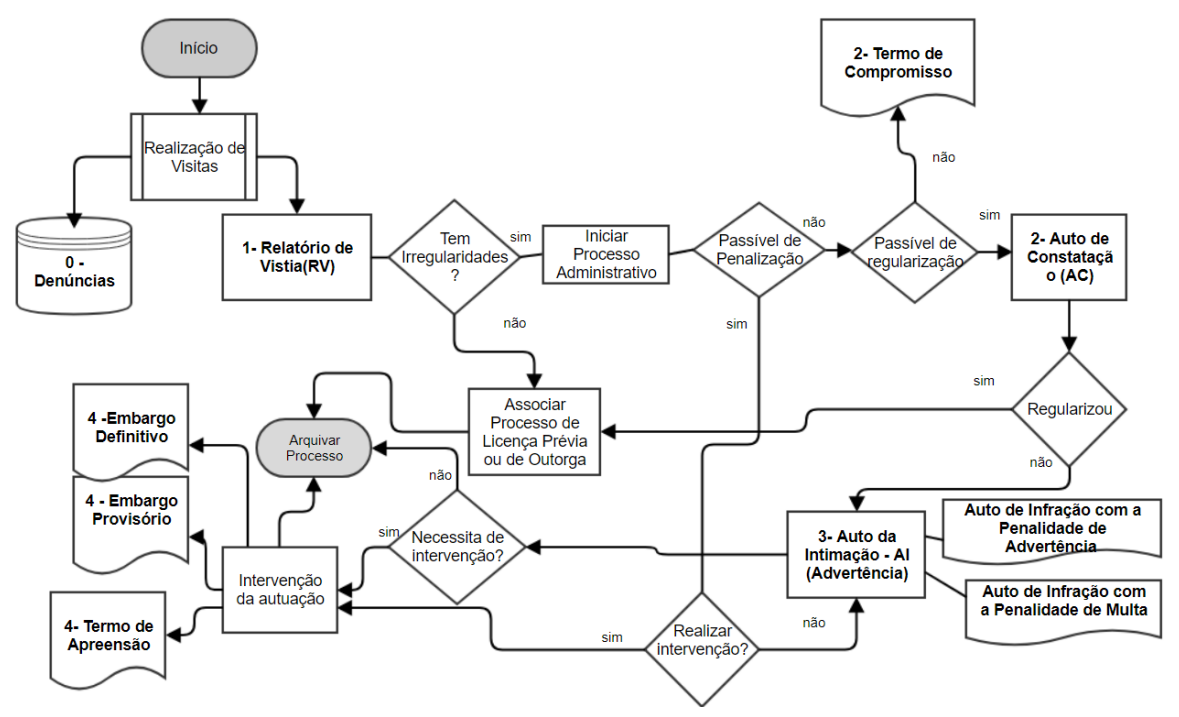

Figura 1. Fluxograma do processo de fiscalização

Os fiscais são responsáveis por realizar visitas para apurar denúncias. As visitas podem ser cadastradas também a partir de uma denúncia. Durante a visita realizada é necessário informar se foram constatadas irregularidades na propriedade visitada. Se não forem constatadas irregularidades a visita é arquivada. Caso contrário, se inicia um processo administrativo, representado pelo Registro de Irregularidade. Um Registro de Irregularidade pode ser realizado de duas formas: Auto de Constatação ou Termo de Compromisso. Estas formas serão ditadas pela característica da irregularidade documentada na visita realizada. Caso a irregularidade seja passível de regularização, será feito um registro do tipo Auto de Constatação, sendo estipulada uma data limite para que $\mathrm{o}$ visitado procure se regularizar junto à AESA e o cumprimento dessa regularização configura um arquivamento do processo. Quando a irregularidade não é passível de regularização, será feito um Termo de Compromisso, no qual o visitado se compromete em cessar com as irregularidades documentadas na visita, dentro de um prazo estabelecido da pactuação dos termos do acordo.

Caso a situação não seja regularizada dentro do prazo estabelecido, a AESA emitirá as infrações através do documento denominado de Auto de Infração. Auto de Infração é fruto do descumprimento de um acordo e pode desencadear em uma penalidade com multa para o autuado, ou em advertência. Caso, após a constatação da infração, seja entendido que também há necessidade de uma intervenção em algum equipamento ou local que continue sendo usado sob forma irregular, é desencadeada uma Intervenção. Caso o uso irregular cesse, o processo é arquivado. Uma intervenção pode representar três ações diferentes: Embargo definitivo, quando o fiscal toma a ação de lacrar o equipamento de uso irregular definitivamente; Embargo provisório, quando o lacre perdura apenas durante um período de tempo estabelecido; e Termo de Apreensão: quando é necessário realizar a apreensão do equipamento que está sob uso irregular. Há de se observar também que tanto os Autos de Infração quanto às Intervenções podem ocorrer imediatamente durante a visita de fiscalização. Isto ocorre quando o fiscal julga realizar imediatamente uma infração ou intervenção para não causar um dano maior aos recursos hídricos. Após a realização da Intervenção, é feito um requerimento de abertura de processo de autuação, no qual encerram-se as competências do setor de fiscalização. Neste requerimento as provas da fiscalização são juntadas para o setor jurídico da AESA para ingressar com ação civil pública em desfavor dos infratores. 


\section{Implementação de uma solução computacional}

O sistema desenvolvido com o propósito de implementar o processo de fiscalização segue a arquitetura ilustrada na Figura 2.

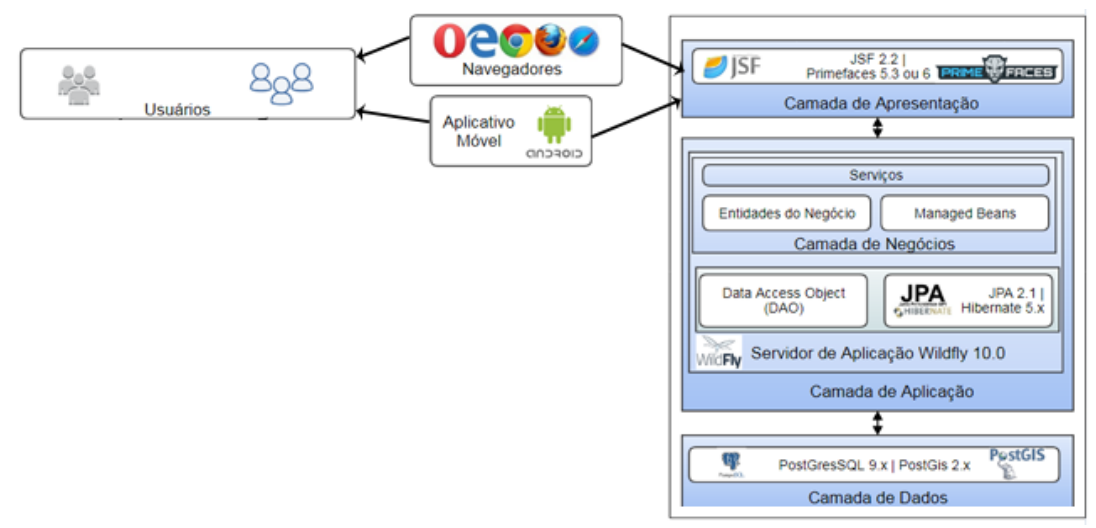

Figura 2. Projeto Arquitetural do Sistema

A arquitetura é dividida em três camadas:

- Camada de Apresentação ( Web / Dispositivos Móveis) : camada responsável por interagir diretamente com o usuário. Observa-se o uso de tecnologias baseadas em componentes para aplicações web e para dispositivos móveis.

- Camada de Aplicação: responsável por prover toda a funcionalidade do sistema. ManagedBeans intermediam a interação entre a camada de apresentação e as funcionalidades do sistema. As Entidades do negócio são responsáveis pelo domínio da lógica de negócio. Os Serviços são responsáveis por prover de fato as funcionalidades do sistema. O Acesso aos Dados abstrai o acesso ao banco de dados através do uso do padrão de projeto DAO e das tecnologias JPA e Hibernate.

- Camada de Dados: responsável por armazenar os dados e manter o controle dos usuários que têm acesso ao sistema. O SGBD utilizado é o PostgreSQL, acrescentado do pacote de expansão de dados espaciais PostGIS.

O Sistema de Fiscalização encontra-se em produção na AESA, podendo ser acessado diretamente no portal da Agência ${ }^{1}$ através dos links relativos à fiscalização.

\subsection{Sistema Web}

A fim de garantir a usabilidade do sistema, optou-se por utilizar nos cadastros integrados no sistema, nomenclatura e estruturas semelhantes àquelas que já eram utilizadas nos formulários impressos pelos funcionários da Agência.

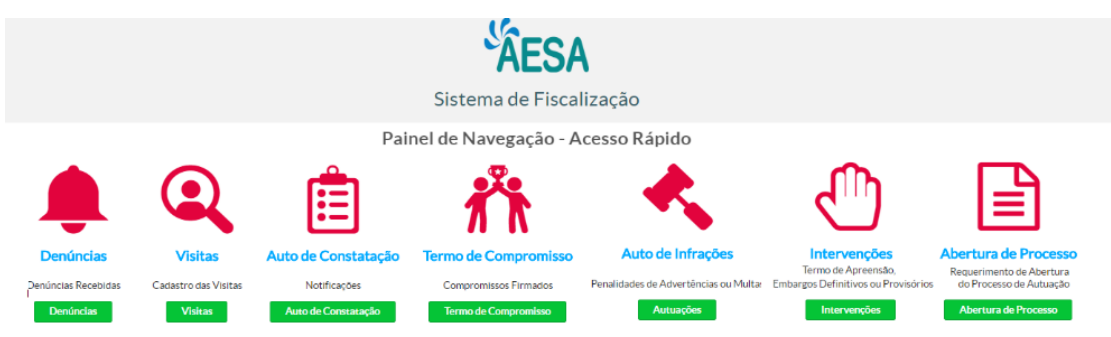

Figura 3. Tela Principal do Sistema

\footnotetext{
${ }^{1}$ http://www.aesa.pb.gov.br
} 
A aplicação possibilita acesso gerencial às entidades que compõem o fluxo do setor de fiscalização, como é possível ver na Figura 3. Cada entidade conta com a sua própria tela de gerenciamento, onde são disponibilizadas funcionalidades equivalentes às necessidades dos funcionários para cada uma das entidades do sistema. Essa divisão organizacional eleva o nível de eficiência nos momentos em que se busca realizar o acesso ou cadastro de algum documento no sistema. Os cadastros de informações são realizados no sistema através do preenchimento dos formulários específicos para cada entidade. A Figura 4 exibe o formulário de cadastro de uma Visita.
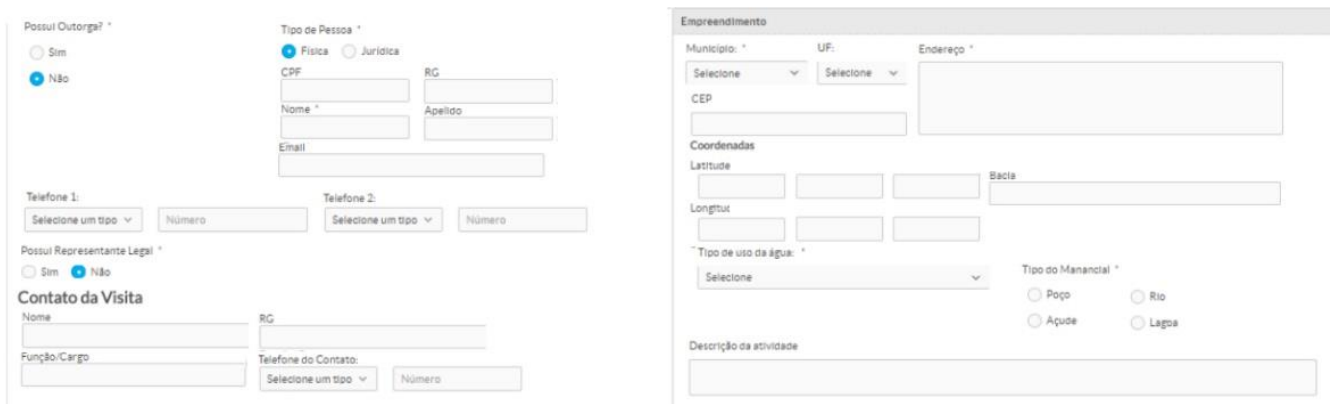

Figura 4. Formulário de Cadastro de Visita

Além do cadastro de visitas e de todo os processos da fiscalização, outro avanço importante é a otimização do gerenciamento e da coleta de denúncias, onde o sistema conta com um gerenciador que foi estrategicamente desenvolvido para possibilitar que as denúncias recebidas, rapidamente, sejam atribuídas a fiscais para que estes possam realizar os processos fiscalizatórios da visita no local denunciado, como é possível ver na Figura 5. Esse recurso possibilita uma maior capacidade de averiguação das denúncias recebidas, além disso, a associação entre as denúncias e os relatórios das visitas realizadas para averiguá-las, permite uma a obtenção de relatórios de desempenho, no que se refere à quantidade de denúncias que são averiguadas efetivamente.

\subsection{Aplicativo para dispositivos móveis}

Para apoiar o fiscal em campo, foi desenvolvido um aplicativo móvel que permite a integração das atividades de realização da visita em campo com o sistema web, permitindo que o fiscal usufrua de recursos semelhantes aos que são disponibilizados no sistema web, mesmo nas localidades remotas, onde não se tem acesso à internet.

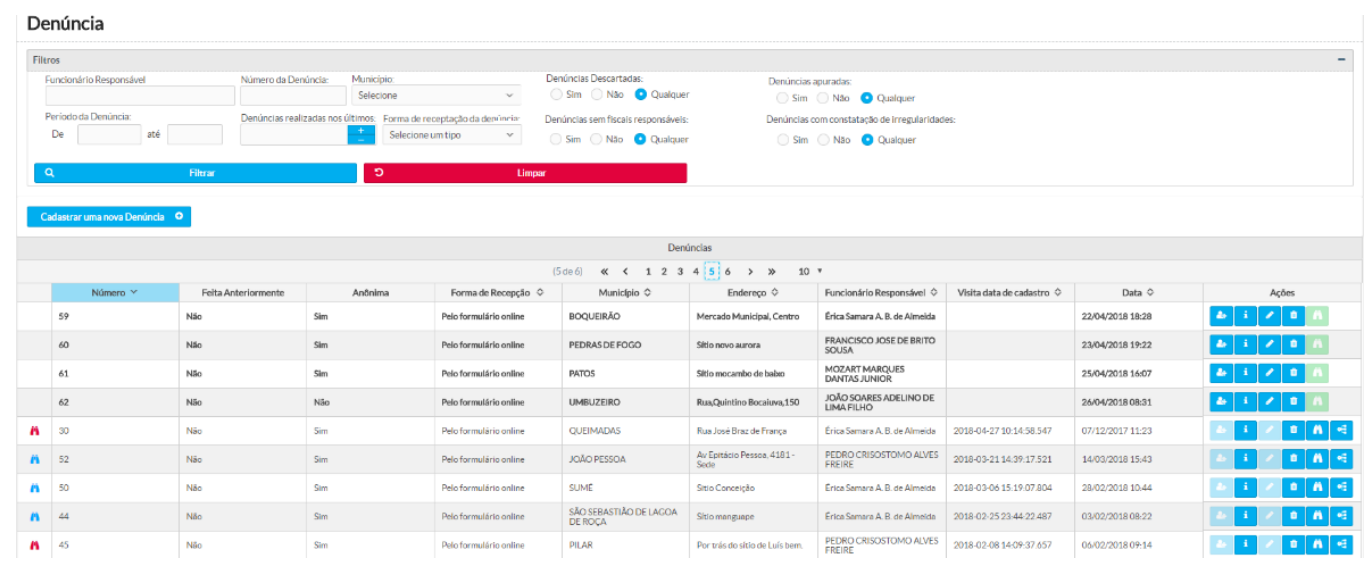

Figura 5. Gerenciador de Denúncia

A possibilidade de importar uma denúncia do banco de dados para o aplicativo 
capacita a equipe de fiscalização a dar continuidade, em campo, às visitas que constam no sistema, como é possível ver na Figura 6, assim como iniciar uma visita a partir de uma denúncia recebida no sistema. Ao final do processo de realização das visitas, quando obtiver acesso à internet, o fiscal poderá exportar o Relatório da Visita e os Autos de Constatação ou Termos de Compromisso decorrentes deste para o sistema, como mostra a Figura 6. Estas informações estarão disponíveis para que os técnicos administrativos e gerentes da AESA possam dar sequência aos processos que decorram destes documentos.

Antes do recurso de importação dos documentos via internet, o processo administrativo só era iniciado quando o fiscal retornava à repartição da AESA e dava entrada no processo com o relatório preenchido em campo à mão, o que tornava o processo moroso, prejudicando a eficiência administrativa da agência e o usuário do equipamento autuado no processo fiscalizatório.

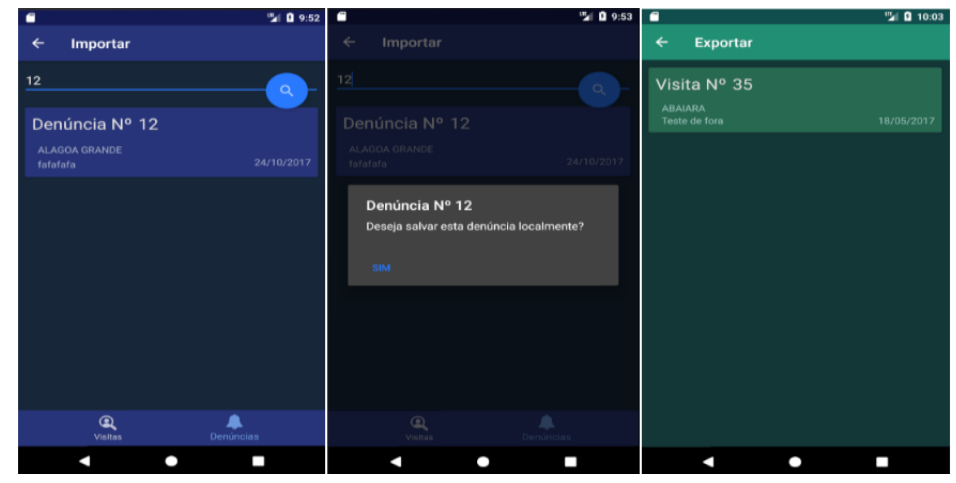

Figura 6 - Importação/ Exportação de Visitas e Denúncias

Quando se transfere o processo de fiscalização para os meios digitais, surge a necessidade de verificação da autenticidade dos documentos persistidos no sistema. Para a autenticação desses documentos na sua forma digital, o aplicativo utiliza um leitor biométrico, conectado ao smartphone do fiscal, que possibilita a coleta e o armazenamento dos dados biométricos de usuário autuado no processo, conforme mostra a Figura 7. A autenticação através da biometria permite à AESA ter um nível maior de confiança nos documentos cadastrados digitalmente por meio da aplicação móvel, prevenindo fraudes e garantindo a validade legal dos documentos.

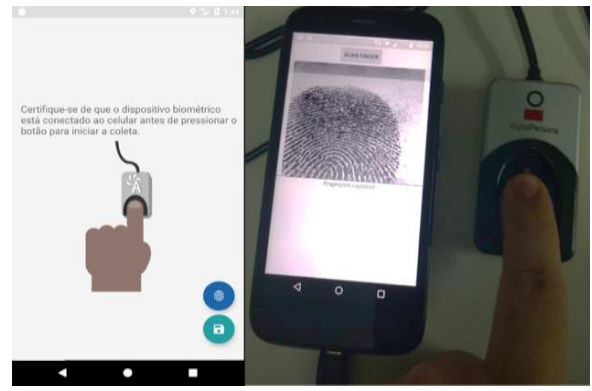

Figura 7: Processo de Coleta dos Dados Biométricos

De modo geral, o aplicativo garante uma melhoria na conformidade dos dados que compõem os documentos que tramitam no setor de fiscalização da Agência de Gestão de Águas. Anteriormente, os fiscais preenchiam o cadastro em papel com os dados inconsistentes e fora de padrão, o que dificultava uma gestão eficaz destas informações no banco de dados da agência. Com o aplicativo, os relatórios das visitas realizadas em campo, seguem para o sistema de forma padronizada, com eficiência. 


\subsection{Resultados parciais}

O sistema está em produção desde 26 de Outubro de 2017. Com a constante utilização do sistema por parte dos funcionários da AESA, o mesmo já conta com diversas visitas e denúncias registradas. É possível realizar uma análise inicial sobre o rendimento do processo fiscalizatório com o apoio do sistema desenvolvido. A partir do gráfico de Denúncias recebidas, na Figura 8 , é possível analisar que, do total de denúncias recebidas, a grande maioria resultou em visitas com constatação de irregularidades, um total de 37 denúncias apuradas com irregularidades, em detrimento de 4 apuradas sem constatações. Além disso, as denúncias apuradas representam $81 \%$ do total de denúncias recebidas, configurando um grau elevado de eficiência nos processos fiscalizatórios que passam pelo sistema desenvolvido.

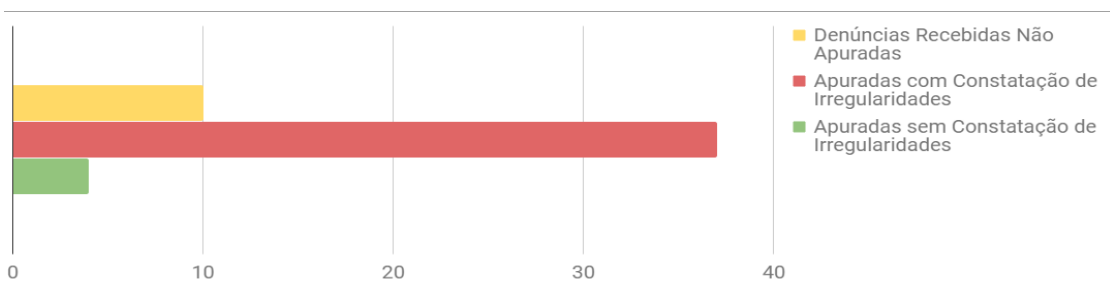

Figura 8: Gráfico de Denúncias Recebidas

\section{Considerações Finais}

Com o objetivo de auxiliar a gestão de recursos hídricos, neste artigo foi apresentado um modelo de processo de fiscalização de uso de água. Tal modelo possibilitou a implementação de uma solução computacional para prover uma gestão da fiscalização de forma eficiente e eficaz. A solução apresentada, já implantada na AESA, utiliza uma arquitetura de sistema de informações baseado na Web e em plataforma móvel, e objetiva o gerenciamento das informações relativas aos atos realizados durante todo o processo de fiscalização. Utiliza também o conceito de crowdsourcing onde a população torna-se também um agente ativo da fiscalização, auxiliando a coleta de denúncias de possíveis infrações dos regulamentos e leis vigentes relativos ao uso da água.

A adoção da solução proposta neste trabalho, embora recente, já tem resultado em um impacto bastante positivo nas ações de fiscalização da agência, inclusive através de sua utilização por parte da população, o que tem permitido uma gestão eficiente e eficaz. Por eficiência, entende-se que os processos tornaram-se mais ágeis, através da tramitação eletrônicas dos processos e ações que ocorrem via smartphone e sistema Web, dando agilidade ao fluxo de informação dentro da agência. Por eficácia, entende-se que, com a centralização das informações, as decisões podem ser tomadas de forma mais segura, baseadas em informações do sistema em tempo real, sendo, portanto, menos propenso a erros de digitação e comunicação. Há, portanto, maior qualidade no trato da informação proveniente das ações de fiscalização do uso da água.

Como trabalhos futuros, várias melhorias no processo de fiscalização podem ser desenvolvidas e implantadas. Uma destas melhorias, seria utilizar técnicas de processamento de textos para reconhecer denúncias já realizadas e/ou apuradas, informando ao usuário a existência de denúncias semelhantes, bem como proteger as entradas de dados contra spammers. Uma outra melhoria seria utilizar informações de balanços hídricos e de outorgas de uso da água para recomendar regiões geográficas que necessitam de uma maior atenção da fiscalização. 


\section{Agradecimentos}

Os autores agradecem a AESA - Agência de Gestão de Águas do Estado da Paraíba e ao CNPQ - Conselho Nacional de Pesquisa Científica e Tecnológica por financiar este projeto.

\section{References}

Erickson, T. (2010). "Geocentric Crowdsourcing and Smarter Cities: Enabling Urban Intelligence in Cities and Regions", In: 12th ACM International Conference on Ubiquituous Computing.

Júnior, C. B. S., Candeias, A. L. B., Cirilo, J. A., Júnior, J. R. T. (2013) “Atlas Eletrônico Analítico como Ferramenta na Gestão dos Recursos Hídricos”, Revista de Geografia (UFPE), v. 30, No. 3, p. 226-243.

Meier, M. A., Costa, F. S., Basso, L. A. (2015) "A Participação Social Na Gestão Dos Recursos Hídricos: Um Paralelo Entre Brasil E Portugal”, In: $12^{\circ}$ Simpósio de Hidráulica e Recursos Hídricos dos países de Língua Portuguesa, Brasília. Gestão da Água e do Território: Perspectivando Sinergias.

Sakamoto, M. S., Andrade, F. C. M., Martins, E. S .P. R., Carvalho, M .S. B. S. (2016) "Sistemas de informações agrometeorológicas da FUNCEME", Agrometeoros, Passo Fundo, v.24, n.1, p.97-106, 2016.

Pereira, G. S., Cavalcanti, B. S. (2016), "Siga: O Novo Sistema De Suporte À Decisão Para Gestão Dos Recursos Hídricos", p. 449-456. In: Anais do XIV Encontro Nacional de Estudantes de Engenharia Ambiental.

Andreis, J.H., Borella, F., Pavan, W., Holbig, C.A., Dalbosco, J., Godoy, C.V. , Fernandes, J.M.. Mobile Application for Asian Soybean Rust Tracking in Brazil. In. WCAMA 2016.

Figueiredo, H. F., Amorim, R.V., Baptista, C.S., Paes, R.F. C., Duarte, B., Pinto, M.S.L.. SISDOC: Uma Biblioteca Digital Multimídia para Gestão de Documentos Ambientais. In: WCAMA 2016.

Alves, A.L.F., Baptista, C.S., Andrade, L.H., Paes, R.F. C.. Uso de Tecnicas de Analise de Sentimentos em Tweets relacionados ao Meio-Ambiente. In: WCAMA 2015.

Santana, J.V., Figueiredo, H. F., Baptista, C.S., Paiva, A.C. Paes, R.F.C., Duarte, B., Pinto, M.S.L.. SISLIC: Um método para gerenciamento do processo de licenciamento ambiental. In WCAMA 2015.

Souza, I.R.C., Souza, I.R.C., Santos, M.S.R., Couto, M.S.. Proposta de Desenvolvimento de um Sistema Web Para Monitoramento Hídrico Residencial. In WCAMA 2015.

Jeronimo, C.L.M., Cruz, I.G.M., Campelo, C.E.C., Baptista, C.S., Rocha, J.H., Pinto, M.S.L., Figueiredo, H. F.. Monitoramento ambiental em bordas de grandes reservatorios hidreletricos. In: WCAMA 2015

Tavares, C.L., Dias, T.L., Rigo, D., Alves, M.H, Luna, K.. SIG como apoio ao Processo de Estudos Hidrológicos para determinar pontos de vazão para outorga. In WCAMA 2011.

Marques, C.M., Guilherme, I. R., Foster, E.G., Assis, E.R.N., Meaulo, F. J. Sistema de apoio à análise da vulnerabilidade natural à poluição do recurso hídrico subterrânea. WCAMA 2009.

Oliveira, C.U.R., Zeilhofer, P.. Sistema de Suporte à Decisão baseado em Lógica Fuzzy para Outorga de Recursos Hídricos Superficiais. In: WCAMA 2017. 